\title{
A five year physiological case study of an Olympic runner
}

A M Jones

\begin{abstract}
Objective-To study physiological changes caused by long term endurance training in a world class female distance runner, and to compare these changes with alterations in $3000 \mathrm{~m}$ running performance.

Methods-The subject underwent regular physiological assessment during the period 1991-1995. Physiological measures made included body composition, maximal oxygen uptake (Vo $\mathrm{VAx}_{2}$ ), running economy, and lactate threshold. In addition, the running speed at $\mathrm{Vo}_{2} \mathrm{MAx}$ was estimated. Test protocols, laboratory equipment, and laboratory techniques used were the same for each test session.

Results-The $3000 \mathrm{~m}$ race performance improved by $8 \%$ from 1991 to 1993 after which it stabilised. In contrast, $\mathrm{Vo}_{2} \mathrm{MAX}$ fell from 1991 (73 $\mathrm{ml} / \mathrm{kg} / \mathrm{min})$ to 1993 (66 $\mathrm{ml} / \mathrm{kg} / \mathrm{min}$ ). Submaximal physiological variables such as lactate threshold (from 15.0 to $18.0 \mathrm{~km} / \mathrm{h}$ ) and running economy (from $53 \mathrm{ml} / \mathrm{kg} / \mathrm{min}$ to $48 \mathrm{ml} / \mathrm{kg} / \mathrm{min}$ at 16.0 $\mathrm{km} / \mathrm{h}$ ) improved over the course of the study. Despite no increase in $\mathrm{Vo}_{2} \mathrm{MAX}$, the reduction in the oxygen cost of submaximal running caused the estimated running speed at $\mathrm{Vo}_{2} \mathrm{MAX}$ to increase from 19.0 $\mathrm{km} / \mathrm{h}$ in 1991 to $20.4 \mathrm{~km} / \mathrm{h}$ in 1995.

Conclusions-Improvement in $3000 \mathrm{~m}$ running performance was not caused by an increase in Vo $\mathrm{Vo}_{2} \mathrm{MAX}$. Rather, the extensive training programme adopted, together perhaps with physical maturation, resulted in improvements in submaximal fitness factors such as running economy and lactate threshold. These adaptations improved the running speed estimated to be associated with $\mathrm{Vo}_{2} \mathrm{MAx}$, and resulted in improved $3000 \mathrm{~m}$ running performance. (Br F Sports Med 1998;32:39-43)
\end{abstract}

Keywords: distance running; performance; training; $\mathrm{VO}_{2} \mathrm{MAX}$; running economy

Department of Exercise and Sport Science, Crewe and Alsager Faculty, the Manchester Metropolitan University, Hassall Road, Alsager ST7 2HL, United Kingdom A M Jones

Correspondence to: Dr A M Jones.

Accepted for publication 9 October 1997
Traditionally, maximal oxygen uptake $\left(\mathrm{VO}_{2} \mathrm{MAX}\right)$ was considered to be the most important physiological measure in the assessment of potential for endurance exercise. ${ }^{1}$ More recently, it has been acknowledged that factors such as the lactate threshold, defined as the submaximal running speed that invokes a sudden and sustained increase in blood lactate concentration, ${ }^{2}$ and the running economy, defined as the energy cost $\left(\mathrm{VO}_{2}\right)$ of submaximal running, ${ }^{3}$ also contribute to endurance running performance. The estimated running speed at $\mathrm{VO}_{2} \mathrm{MAX}$ (a composite measure of
$\mathrm{VO}_{2} \mathrm{MAX}$ and running economy), ${ }^{4}$ and the maximum running speed attained in a fast incremental treadmill test ${ }^{5}$ have also been successfully used to predict performance in distance running events. However, there are limited data on the changes in these measures caused by long periods of endurance training and their longitudinal relations with endurance performance, particularly for female athletes.

This paper reports the results of a five year long study of a world class female distance runner. The runner, who was 17 years of age on commencement of the study in 1991, won the World Junior cross country championships in 1992, and has since been placed in the first seven runners in the World Championships $(3000 \mathrm{~m})$ and the Olympic Games $(5000 \mathrm{~m})$. Physical and physiological variables determined at regular intervals throughout the study included body composition, $\mathrm{VO}_{2} \mathrm{MAX}$, lactate threshold, running economy, estimated running speed at $\mathrm{VO}_{2} \mathrm{MAX}$, and maximum running speed attained in a fast incremental treadmill test. These measures were used to provide a comprehensive picture of adaptations in the physiology of the runner to training. The purpose of this study was: (a) to describe the physiology of a world class female distance runner; (b) to investigate changes caused by long term endurance training in the physiological measures listed above and the relations between these variables; and (c) to examine how changes in physiological function affect distance running performance.

\section{Methods}

The study received approval from the Chelsea School ethics committee, University of Brighton. Thereafter, the subject underwent two physiological assessment sessions per year, usually in March-April and NovemberDecember. To improve confidence that changes observed over time were due to real physiological changes and not to the combined effect of diurnal biological variability and technical or measurement error, the results of these two test sessions were averaged for each year of study. Exactly the same procedures and equipment were used for each test session, and the tests commenced at the same time of day $(10-11 \mathrm{am})$. The subject was instructed to train only lightly in the 48 hours preceding a test session, and to arrive at the laboratory in a fully hydrated state, at least two hours after eating. After she had given written informed consent, the subject's height and body mass were measured, and the sum of four skinfolds was taken to provide an estimate of body composition. $^{6}$ 
Table 1 Changes in various physical and physiological measures over five years of endurance training

\begin{tabular}{lrrrrr}
\hline & 1991 & 1992 & 1993 & 1994 & 1995 \\
\hline Body mass (kg) & 51.3 & 52.2 & 53.0 & 54.4 & 52.5 \\
Body fat $(\%)$ & 15.7 & 13.4 & 11.8 & 15.7 & 14.1 \\
Lactate threshold $(\mathrm{km} / \mathrm{h})$ & 15.0 & 16.5 & 17.0 & 18.0 & 18.0 \\
[Lactate] at $17 \mathrm{~km} / \mathrm{h}(\mathrm{mM})$ & 3.7 & 2.8 & 1.6 & 1.6 & 1.4 \\
Maximum speed $(\mathrm{km} / \mathrm{h})$ & 19.5 & 21.0 & 22.5 & 22.0 & 22.0 \\
\hline
\end{tabular}

For all treadmill testing, the treadmill grade was set at $1 \%{ }^{7}$ The test session was divided into two parts. In the first part, the subject performed seven to nine submaximal exercise stages of three minutes duration. Running speeds selected were in the range of 14.0-19.0 $\mathrm{km} / \mathrm{h}$, and running speed was increased by 0.5 $\mathrm{km} / \mathrm{h}$ between stages. During the last minute of each stage, expired air was collected in a Douglas bag. Heart rate was determined throughout the test by telemetry (Polar Electro, Kempele, Finland), and was recorded at the completion of each stage. A $20 \mu \mathrm{l}$ fingertip capillary blood sample was taken during a 20 second break between stages for duplicate determination of whole blood lactate concentration by micro-assay (Analox GM7 Hammersmith, UK). The coefficient of variation for blood lactate determination was $2.8 \%$ for ten samples in the physiological range $(5 \mathrm{mM})$. When the blood lactate concentration determined for the penultimate submaximal stage exceeded $4 \mathrm{mM}$, the treadmill speed was kept constant and the treadmill grade was increased by $1 \%$ each minute until volitional exhaustion. During this period, expired air was collected in Douglas bags over the final 45 seconds of each one minute stage for determination of $\mathrm{VO}_{2} \mathrm{MAX}$. This procedure has been shown to provide a valid assessment of $\mathrm{VO}_{2} \mathrm{MAX}^{8}$

For determination of respiratory gas exchange variables, expired air was analysed for the concentrations of $\mathrm{O}_{2}$ and $\mathrm{CO}_{2}$ by sampling through a paramagnetic transducer (Servomex Series 1100, Crowborough, Sussex, UK) and an infrared analyser (Servomex, model 1490) respectively. Volumes were determined by using a dry gas meter (Harvard Ltd, Edenbridge, Kent, UK).

$\mathrm{VO}_{2} \mathrm{MAX}$ was considered to be the highest $\mathrm{VO}_{2}$ recorded during part one of the test session. The lactate threshold was determined as a clear threshold increase in blood lactate from plots of blood lactate against running speed. Running economy was defined as the $\mathrm{VO}_{2}$ required to run at $16.0 \mathrm{~km} / \mathrm{h}$. ${ }^{3}$ The running speed at $\mathrm{VO}_{2} \mathrm{MAX}$ was estimated by solving the regression equation relating $\mathrm{VO}_{2}$ to running speed (running speed $\left.=\mathrm{m}\left(\mathrm{VO}_{2}\right)+\mathrm{c}\right)$ for $\mathrm{VO}_{2} \mathrm{MAX}^{4}{ }^{4}$ The regression equation was derived only from data collected at running speeds below the lactate threshold, since the kinetics of $\mathrm{VO}_{2}$ are considerably more complex above this exercise intensity. ${ }^{9}$

After two hours recovery, the subject performed the second part of the test session. She began running at $12 \mathrm{~km} / \mathrm{h}$, and running speed was increased by $0.5 \mathrm{~km} / \mathrm{h}$ on the completion of successive $200 \mathrm{~m}$ intervals until volitional exhaustion was reached. ${ }^{10}$ Maximum running

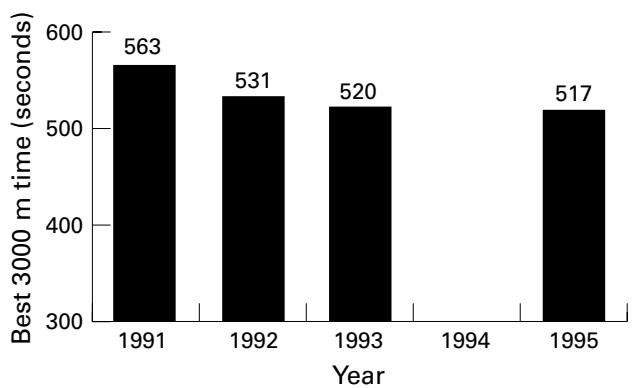

Figure 1 Improvement in best time from 1991 to 1995. The subject was injured in 1994.

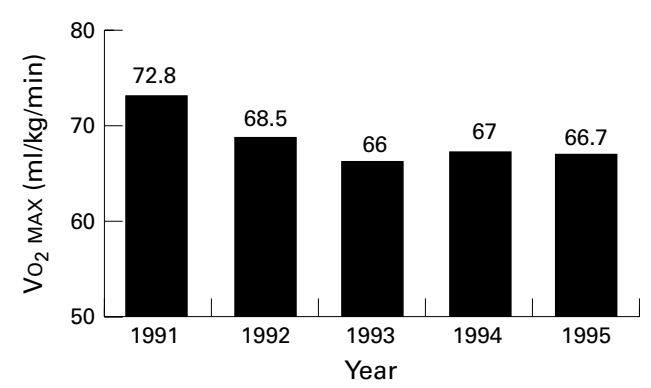

Figure 2 Changes in maximum oxygen uptake ( $\mathrm{VO}_{2} \mathrm{MAX}$ ) from 1991 to 1995.

speed was defined as the running speed attained in the final completed stage.

\section{Results}

Over the period of study, the subject gained 6 $\mathrm{cm}$ in stature $(1.68-1.74 \mathrm{~m})$. Body mass increased slightly and percentage body fat varied between 11.8 and $15.7 \%$ (table 1 ).

Figure 1 shows the subject's $8 \%$ improvement in $3000 \mathrm{~m}$ race time (her specialist distance) from 1991 to 1995 . The subject did not compete in 1994 because of injury. This improvement in the performance criterion is in contrast with a $9 \%$ reduction in $\mathrm{VO}_{2} \mathrm{MAX}$, from 72.8 to $66.0 \mathrm{ml} / \mathrm{kg} / \mathrm{min}$, observed over the same period (fig 2). Maximal heart rate fell from 203 beats/minute in 1991 to 197 beats/minute in 1995.

Of the submaximal measures, there was a marked reduction in the blood lactate concentration measured at a reference submaximal running speed and a $20 \%$ improvement in lactate threshold over the period of study (table 1). Further, there was an $11 \%$ reduction in the $\mathrm{VO}_{2}$ required to run at $16 \mathrm{~km} / \mathrm{h}$ - that is, an improved running economy-between 1992 and 1995 (fig 3). Note that a running economy measure for 1991 is omitted since, in that year, the lactate threshold was lower than $16.0 \mathrm{~km} / \mathrm{h}$.

The improved running economy over the entire submaximal range offset the lack of improvement in $\mathrm{VO}_{2} \mathrm{MAX}$ insofar as the estimated running speed at $\mathrm{VO}_{2} \mathrm{MAX}$ improved from $19.0 \mathrm{~km} / \mathrm{h}$ in 1991 to $20.4 \mathrm{~km} / \mathrm{h}$ in 1995 (fig 4). The estimated running speed at $\mathrm{VO}_{2} \mathrm{MAX}$ closely predicted the season's best running speed for $3000 \mathrm{~m}$. The maximum speed attained in the fast incremental treadmill test reflected the overall improvement in aerobic fitness up to 1993, but was not sensitive to improvement in the performance criterion later in the study period (table 1). 


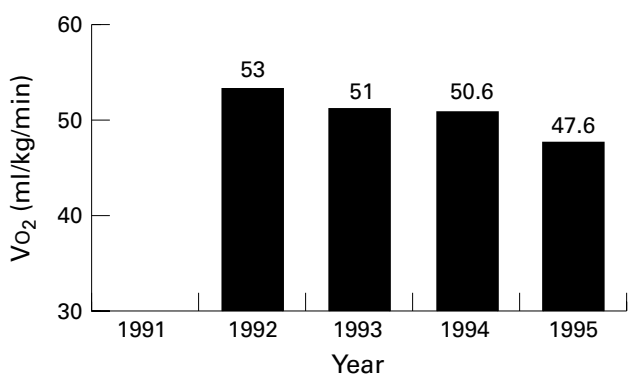

Figure 3 Reduced oxygen cost of submaximal running - that is, improved running economy-from 1992 to 1995 . Data presented are for $16 \mathrm{~km} / \mathrm{h}$ and $1 \%$ treadmill grade.

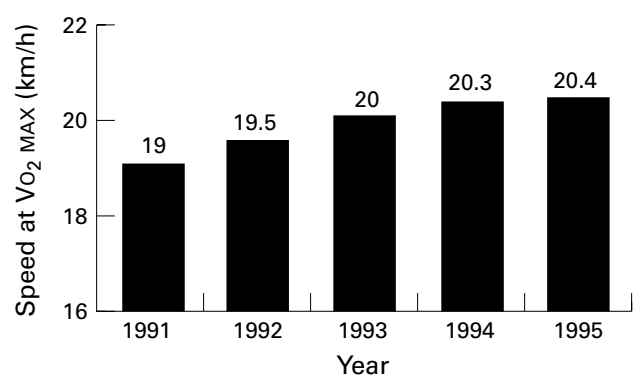

Figure 4 Improvement in the estimated running speed at maximum oxygen uptake (V $\mathrm{O}_{2} \mathrm{MAX}$ ) from 1991 to 1995.

\section{Discussion}

The purpose of this study was to investigate changes in physiological variables induced by long term endurance training in a world class female distance runner, and to study, longitudinally, the influence of these variables on an endurance performance criterion.

There was a substantial improvement in $3000 \mathrm{~m}$ race performance over the course of the study, with the subject's best times for the season being consistently ranked amongst the best in the world for that year. The lack of improvement in the $3000 \mathrm{~m}$ performance criterion in 1995 coincided with the introduction of the $5000 \mathrm{~m}$ event for women in major championships, and reflects altered priorities and a reduced competitive opportunity at 3000 $\mathrm{m}$. It is interesting to compare changes in maximal and submaximal physiological variables with the improvement in race performance. Limited data are available on the physiological status of elite female distance runners, but the $\mathrm{VO}_{2} \mathrm{MAX}$ of $67-73 \mathrm{ml} / \mathrm{kg} / \mathrm{min}$ consistently recorded in the present subject is similar to or slightly higher than the $65-70$ $\mathrm{ml} / \mathrm{kg} / \mathrm{min}$ proposed as typical for senior internationals by Neumann. ${ }^{11}$ Figure 2 suggests that $\mathrm{VO}_{2}$ MAX fell from 1991 to 1993 after which it stabilised. While variability in $\mathrm{VO}_{2} \mathrm{MAX}$ assessment (including both technical error and diurnal biological variability) has been suggested to be of the order of $4-5 \%,{ }^{12}$ there are several reasons which point to the trend for the reduction and subsequent stabilisation of $\mathrm{VO}_{2} \mathrm{MAX}$ to be real, and not an artefact of the variability in data collection or analysis. These reasons include the following. (1) The subject was highly motivated and the exercise test technicians were satisfied that the subject ran to complete exhaustion on each occasion that $\mathrm{VO}_{2} \mathrm{MAX}$ was measured. (2) Data from the two tests performed in each year were averaged. (3) The day to day coefficient of variation in $\mathrm{VO}_{2}$ determination using the expired gas collection and analysis system in the exercise laboratory used has been reported to be $2.1 \% .^{13}$

It has been suggested that absolute $\mathrm{VO}_{2} \mathrm{MAX}$ peaks at about 15 years of age in the sedentary female and that subsequent reduction in $\mathrm{VO}_{2}$ MAX is partly the result of a decline in maximum heart rate with age. ${ }^{14}$ The $9 \%$ reduction in $\mathrm{VO}_{2} \mathrm{MAX}$ between 1991 and 1993 coincided with a $2 \%$ reduction in maximum heart rate (from 203 to 199 beats/minute). Interpretation of the longitudinal physiological changes observed and their relation to long term endurance training is, however, further complicated by the physical growth and maturation of the subject. There is no evidence to suggest that the subject's $6 \mathrm{~cm}$ gain in stature over the period of study would adversely affect $\mathrm{VO}_{2}$ MAX. ${ }^{15}$ However, if increased height was mediated by an increase in leg length, then some change in running economy and maximum running speed might be hypothesised. Information on relative changes in the length of body segments is not available, but cross sectional studies have shown no clear relation between leg length and stride length, or stride length and running economy. ${ }^{16}$ It is likely, though, that a gain in lean tissue mass, possibly including bone mass and "non-propulsive" muscle mass, was responsible for some of the reduction in $\mathrm{Vo}_{2} \operatorname{MAX}$ between 1991 and 1993 since body mass increased by $1.7 \mathrm{~kg}$ and the estimated percentage body fat decreased in this period (table 1).

Running economy improved over the course of the study period (fig 3). Although fig 3 presents $\mathrm{Vo}_{2}$ data for $16 \mathrm{~km} / \mathrm{h}$, running economy improved over the entire submaximal range measured $(14.0-18.0 \mathrm{~km} / \mathrm{h})$ with training. An association between improved performance and improved running economy is not unexpected. It has been shown that running economy can discriminate performance capability in groups of subjects who are homogeneous for $\mathrm{VO}_{2} \mathrm{MAX},{ }^{3}$ and that subjects with good running economy can frequently outperform subjects with higher $\mathrm{VO}_{2} \mathrm{MAX}$ values. ${ }^{17}$ In one of the few previously reported longitudinal case studies involving elite runners, Conley et $a l^{18}$ reported improved running economy without improvement in $\mathrm{VO}_{2} \mathrm{MAX}$ after training in the miler, Steve Scott. The factors involved in the determination of running economy remain unclear, but both biomechanical factors involved in running style and physiological factors are probably involved. It has been suggested that a greater relative reliance on the $\alpha$-glycerophosphate shuttle over the malate-aspartate shuttle in type II muscle may reduce the $\mathrm{P}: \mathrm{O}$ ratio in the type II fibre compared with the type I fibre. ${ }^{19}$ This would predict a greater $\mathrm{VO}_{2}$ for any given ATP resynthesis rate in type II muscle. A delayed recruitment of type II motor units, as might result from the greater oxidative capacity of muscle seen with endurance training, ${ }^{20}$ would reduce the $\mathrm{VO}_{2}$ required to run at given submaximal speeds. Further, it has been 
reported that transformation of muscle fibre types from type IIb to type IIa, ${ }^{21}$ and from type IIa to type I, ${ }^{22}$ can occur with extensive endurance training. A greater proportion of type I fibres in the musculature has been reported to reduce the energetic cost of treadmill running. ${ }^{23}$

Whatever the cause, the reduced oxygen cost of running throughout the range of submaximal exercise was fundamental in increasing the estimated running speed at $\mathrm{VO}_{2} \mathrm{MAX}$ over time, ${ }^{4}$ since $\mathrm{VO}_{2} \mathrm{MAX}$ was essentially unaltered after 1993. The substitution of $\mathrm{VO}_{2} \mathrm{MAX}$ by the running speed at $\mathrm{VO}_{2} \mathrm{MAX}$, involving the interplay of $\mathrm{VO}_{2} \mathrm{MAX}$ and running economy, has been shown to be highly predictive of success in distance running events. ${ }^{4}$ In the present study, the estimated running speed at $\mathrm{VO}_{2} \mathrm{MAX}$ was a close approximation of the best running speed maintained for $3000 \mathrm{~m}$ during the season. This supports work suggesting that $3000 \mathrm{~m}$ running requires the utilisation of approximately $100 \%$ $\mathrm{VO}_{2}$ MAX. $^{24}$ This sensitivity of the estimated running speed at $\mathrm{VO}_{2}$ MAX to training, and its close association with distance running performance, supports the suggestion of Morgan et al that the estimation of running speed at $\mathrm{VO}_{2} \mathrm{MAX}$ may be a useful adjunct in the physiological assessment of the elite runner. In contrast, the maximum running speed attained in the fast incremental treadmill test (part two of the test battery) was not sensitive to improvement in athletic performance after 1993. The nonsteady state nature of the test protocol ${ }^{9}$ and the associated requirements for a large contribution of anaerobic processes to ATP resynthesis, and for skill in high speed running, may obscure the measurement of improvement in aerobic fitness by such tests.

Other changes in physiological variables included an elevation of the lactate threshold and a reduction in the heart rate and the blood lactate concentration measured at representative submaximal running speeds (table 1). There is controversy over the nature of the blood lactate response to exercise, ${ }^{25}$ with some groups disputing the existence of a threshold phenomenon. ${ }^{26}{ }^{27}$ However, a number of the studies that have described a continuous increase in blood lactate during incremental exercise may be criticised for using protocols that are likely to obscure threshold detection-that is, they have used rapid incremental rates that produce few data points or they have initiated exercise tests at high relative intensities. It has been shown that two-component linear regression analysisthat is, a single threshold model-provides a closer fit to the blood lactate $-\mathrm{Vo}_{2}$ relationship during exercise than does an exponential plus constant model, ${ }^{28}$ with the exponential model producing a very poor fit to blood lactate data in the region of interest $(1.0-4.5 \mathrm{mM}){ }^{29}$ Numerous studies testify to the validity and reliability of lactate threshold determination by visual inspection, ${ }^{30}{ }^{31}$ and the use of multistage test protocols with stage durations of three to four minutes, and small intensity increments (as in the present study) further simplifies threshold identification. ${ }^{32}$
The sensitivity of lactate threshold to endurance training is well documented, ${ }^{33}$ and the running speed at which lactate threshold occurs has been shown to dictate the speed that can be sustained during distance running races. ${ }^{2}{ }^{34}$ The running speed at which lactate threshold occurred increased from approximately six minutes and 25 seconds per mile in 1991 to five minutes and 20 seconds per mile in 1995. This represents a $20 \%$ improvement in the running speed at lactate threshold in four years, and is indicative of a greatly enhanced endurance capacity. The exercise intensity associated with lactate threshold increased from approximately $80 \% \mathrm{VO}_{2} \mathrm{MAX}$ in 1991 to $88 \% \mathrm{VO}_{2} \mathrm{MAX}$ in 1995. The importance of a high lactate threshold to the performance of the fast aerobic events of $3000 \mathrm{~m}$ and $5000 \mathrm{~m}$ is underlined by data demonstrating that time to exhaustion at $\mathrm{VO}_{2} \mathrm{MAX}$ is positively related to the percentage $\mathrm{VO}_{2} \mathrm{MAX}$ at which lactate threshold occurs. ${ }^{35}$ Interestingly, the rightward shift in the heart rate-running speed relation with training resulted in there being little change in the heart rate associated with the lactate threshold over time. Of practical interest to athletes and coaches without access to laboratory based physiological assessment is the sensitivity of heart rate at submaximal running speeds to training status. For example, the heart rate measured at $17.0 \mathrm{~km} / \mathrm{h}$ fell from 199 beats/minute to 180 beats/minute over the course of the study. Routine measurement of heart rate response to several treadmill running speeds might prove useful to the coach in assessing the efficacy of endurance training prescriptions over time.

While specific details relating to training are not available, in general, the development of the training programme reflected the transition of the subject from promising junior to senior international. In later years, particular emphasis was placed on the development of a sound aerobic "base", and, to this end, average weekly training mileage was progressively increased from 30-40 miles a week to 70-90 miles a week. Of interest concerning the physiological improvements observed in the present study was the subject's tendency to perform "steady" mileage at training intensities close to, or at, lactate threshold. This may have been particularly important in the development of lactate threshold. ${ }^{33}{ }^{36}$ The continued improvement in running economy and lactate threshold might be considered important in the future attainment of success in the $5000 \mathrm{~m}$ and $10000 \mathrm{~m}$ track events.

In summary, this study, which is the first to present data on the physiological changes accompanying training in a world class female distance runner over a number of years, showed improved $3000 \mathrm{~m}$ running performance without an improvement in maximal oxygen consumption. Submaximal physiological variables including running economy and lactate threshold improved considerably, and the lower oxygen cost of running at submaximal speeds was important in increasing the running speed estimated to be associated with 
$\mathrm{VO}_{2} \mathrm{MAX}$. The latter measure was the best predictor of $3000 \mathrm{~m}$ running performance.

1 Saltin B, Astrand PO. Maximal oxygen uptake in athletes. $\mathcal{F}$ Appl Physiol 1967;23:353-358.

2 Kumagai S, Tanaka K, Matsuura Y, et al. Relationships of the anaerobic threshold with the $5 \mathrm{~km}, 10 \mathrm{~km}$, and 10 mile races. Eur $\mathcal{F}$ Appl Physiol 1982;49:15-23.

3 Conley DL, Krahenbuhl GS. Running economy and distance running performance of highly trained athletes. Med Sci Sports Exerc 1980;12:357-60.

4 Morgan DW, Baldini FD, Martin PE, Kohrt WM. Ten kilometer performance and predicted velocity at $\mathrm{VO}_{2}$ max among well-trained male runners. Med Sci Sports Exerc 1989;21:78-83.

5 Noakes TD, Myburgh KH, Schall R. Peak treadmill velocity during the $\mathrm{VO}_{2} \max$ test predicts running performance. $f$ Sports Sci 1990;8:35-45.

6 Durnin JVGA, Womersley J. Body fat assessed from total body density and its estimation from skinfold thickness: measurements on 481 men and women aged from 16 to 72 years. Brit f Nutr 1974;32:77-97.

7 Joars. Brit f Nutr $1974 ; 32: 77-97$. Jones AM, Doust JH. A $1 \%$ treadmill grade most accurately reflects the ener.

8 Jones AM, Doust JH. A comparison of three treadmill protocols for the determination of maximal aerobic power in runners. F Sports Sci 1996;14:89.

9 Poole DC, Ward SA, Gardner GW, Whipp BJ. Metabolic and respiratory profile of the upper limit for prolonged exercise in man. Ergonomics 1988;31:1265-79.

10 Conconi F, Ferrari M, Ziglio PG, et al. Determination of the anaerobic threshold by a noninvasive field test in runners. $\mathcal{F}$ Appl Physiol 1982;52:869-73.

11 Neumann G. Special performance capacity. In Dirix A, Knuttgen HG, Tittel K, eds. The Olympic book of sports medicine, vol 1. Oxford: Blackwell Scientific Publications, 1988.

12 Katch VL, Sady SS, Freedson P. Biological variability in maximum aerobic power. Med Sci Sports Exerc 1982;14:215 .

13 James DV, Doust JH. Reliability of pulmonary $\mathrm{Vo}_{2}$ measurement and implications for determination of recovmeasurement and implications for determ

14 Krahenbuhl GS, Skinner JS, Kohrt WM. Developmental aspects of maximal aerobic power in children. Exerc Sport Sci Rev 1985;14:503-38.

15 Astrand PO, Rodahl K. Textbook of work physiology, 3rd ed. New York: McGraw-Hill, 1986: 330-8, 396-8.

16 Cavanagh PR, Kram R. Stride length in distance running: velocity, body dimensions and added mass effects. In Cavanagh PR, ed. Biomechanics of distance running. Champaign Human Kinetics, 1990:35-63.

17 Daniels JT. A physiologist's view of running economy. Med Sci Sports Exerc 1985;17:332-8.

18 Conley DL, Krahenbuhl GS, Burkett LN, Millar AL. Following Steve Scott: physiological changes accompanying training. Physician and Sports Medicine 1984;12:103-6.

19 Schantz PG, Henriksson J. Enzyme levels of the NADH shuttle systems: measurements in isolated muscle fibres from humans of differing physical activity. Acta Physiol Scand 1987;129:505-15.

20 Holloszy JO, Coyle EF. Adaptations of skeletal muscle to endurance exercise and their metabolic consequences. $\mathcal{F}$ Appl Physiol 1984;56:831-8.

21 Andersen P, Henriksson J. Training induced changes in the subgroups of human type II skeletal muscle fibres. Acta Physiol Scand 1977;99:123-5.

22 Baumann $\mathrm{H}$, Jaggi $\mathrm{M}$, Soland $\mathrm{F}$, et al. Exercise training induces transitions of myosin isoform subunits within histochemically typed human muscle fibres. Pflugers Arch 1987;409:349-60.

23 Bosco C, Montanari G, Ribacchi R, et al. Relationship between the efficiency of muscular work during jumping and the energetics of running. Eur f Appl Physiol 1987;56: $138-43$.

24 Leger L, Mercier D, Gauvin L. The relationship between \% $\mathrm{VO}_{2}$ max and running performance time. In: Landers DM, ed. Sport and elite performers. Champaign, IL: Human Kinetics, 1986:113-19.

25 Morton RH. Comment on "Ventilation and blood lactate increase exponentially during incremental exercise". $f$ Sports Sci 1993;11:371-5.

26 Dennis SC, Noakes TD, Bosch AN. Ventilation and blood lactate increase exponentially during incremental exercise. f Sports Sci 1992;10:437-49.

27 Hughson RL, Weisiger KH, Swanson GD. Blood lactate concentration increases as a continuous function in progressive exercise. 7 Appl Physiol 1987;62:1975-81.

28 Beaver WL, Wasserman K, Whipp BJ. Improved detection of lactate threshold during exercise using a log-log transformation. f Appl Physiol 1985;59:1936-40.

29 Wasserman K, Beaver WL, Whipp BJ. Gas exchange theory and the lactic acidosis (anaerobic) threshold. Circulation 1990;81(Suppl II):14-30.

30 Davis JA, Vodak P, Wilmore JH, et al. Anaerobic threshold and maximal aerobic power for three modes of exercise. $\mathcal{F}$ Appl Physiol 1976;41:544-50.

31 Yoshida T, Nagata A, Muro M, et al. The validity of anaerobic threshold determination by a Douglas bag method compared with arterial blood lactate concentration. Eur $\mathcal{F}$ Appl Physiol 1981;46:423-30.

32 Weltman A, Snead D, Steim P, et al. Reliability and validity of a continuous incremental treadmill protocol for the determination of lactate threshold, fixed blood lactate concentrations, and $\mathrm{VO}_{2}$ max. Int $\mathcal{F}$ Sports Med 1990;11:26-32.

33 Londeree BR. Effect of training on lactate/ventilatory thresholds: a meta-analysis. Med Sci Sports Exerc 1997;29: 837-43.

34 Fay L, Londeree BR, Lafontaine TP, Volek MR. Physiological parameters related to distance running performance in female athletes. Med Sci Sports Exerc 1989;21:319-24.

35 Billat V, Renoux J, Pinoteau J, et al. Reproducibility of running time to exhaustion at $\mathrm{VO}_{2}$ max in sub-elite runners. Med Sci Sports Exerc 1994;26:254-7

36 Henritze J, Weltman A, Schurrer RL, Barlow K. Effects of training at and above the lactate threshold on the lactate threshold and maximal oxygen uptake. Eur f Appl Physiol 1985;54:84-8.

\section{Commentary}

This is a longitudinal study of an athlete's maturation to elite status, the kind of topic more often tackled anecdotally in the coaching literature than on the basis of scientific tests, as it is here. So I find Andrew Jones' paper both interesting and valuable.

The athlete was only 17 when the study began. Consequently, the effects of training cannot be separated cleanly from those of the last stages of growth. Nonetheless, perhaps the most powerful finding, which is that $\mathrm{VO}_{2} \mathrm{MAX}$, although extremely high throughout, actually falls a few percent while performance improves by a similar margin, makes its point irrespective of whether training or maturation was the main factor in the improvement. The laboratory tests that do correlate well with track performance are those of lactate threshold, running economy, and estimated speed at $\mathrm{Vo}_{2} \mathrm{MAX}$. These findings nicely confirm results from several cross sectional studies of recent years. 